\title{
GABRIEL ZAID
}

\section{Economía y felicidad}

T a astronomía es una de las ciencias más antiguas, y durante Lmilenios anunció desgracias. Todavía en la Edad Media señalaba días malos en el calendario, dies mali en latín, dismals en inglěs. Pero no se decía que fuera una "dismal science", una ciencia nefasta. ¿Por qué se dice de la economía?

La astronomía nunca se propuso mejorar el cielo, optimizar la aparición de los cometas o hacer un fine tuning del ciclo de la. luna. Podemos criticar los métodos y los resultados de la astronomía antigua, pero no su temple científico: nació como una ciencia de observadores que no participaban en los hechos celestes y que trataban de integrar sus observaciones en teorías. En cambio, la economía nació como la administración. Desde sus origenes, busca mejorar las realidades estudiadas: el patrimonio de la casa, la riqueza de las naciones.

En el economista se complican dos voluntades: la de estudiar científicamente y la de mejorar. Són voluntades presididas por valores muy distintos, que se complican además con millones de voluntades, La sociedad no es un conjunto de objetos inertes, como los que estudia la astronomía. Opone resistencia al estudio y a la intervención.

Alguna vez, cuando los industriales mexicanos ya habían sustituido las importaciones más obvias, se volvió necesario descubrir oportunidades remanentes, ocultas en las agregaciones estadísticas. En el mercado se observaban productos de importación que pudieran tener demanda suficiente para justificar la producción local. Pero, ¿cómo saberlo? Muchos despachos de investigación hacían estudios que pagaban los interesados. Y no faltó quien tuviera la brillante idea de estudiar sin pagar, logrando que la Se cretaría de Industria y Comercio pusiera el producto de interés Lajo el régimen de permiso previo. A través de los permisos, que eran públicos, se observaría el mercado: quiénes y cuánto importaban. 
Pero ¿qué sucedía cuando un producto se ponía bajo el régimen de permiso previo? Que el mercado se asustaba. Era el anuncio de que alguien intentaba la sustitución. Aunque la importación continuaba, en cualquier momento quedaría prohibida, bajo el supuesto de que ya se producía en México. Lo cual iba a ser muy teórico en los primeros años. La producción mexicana podía fallar en calidad, al menos para ciertos usos; o en cantidad, con riesgo de paralizar las actividades de los compradores; y siempre resultaba más cara. En previsión de todo lo cual, lo único razonable era importar en grandes cantidades, mientras fuera posible, para tener reservas almacenadas. Lo cual mandaba señales falsas al observador de las importaciones: parecía que el mercado era mayor de lo que era. La presencia del observador modificaba la realidad observada, y generaba un desperdicio de inversiones y divisas: primero de importaciones excesivas, luego de bienes de capital e insumos para sustituirlas.

La nomía de la astronomía es estudiable pero no modificable. Las leyes del cielo no son decretos de la tierra. En cambio; las realidades económicas se mueven bajo dos tipos de leyes: las que pudiéramos llamar "físicas", como la ley de Gresham (la mala moneda saca de circulación a la buena), y las que se decretan. La nomía de la economía es estudiable pero también modificable. De hecho, lo que se estudia nunca puede ser una realidad modificada por intervenciones previas. A veces, modificada por el hecho mismo de estudiarla.

Aunque algunos economistas quisieran estudiar la economía como los astrónomos estudian las estrellas, sin soñar con intervenir, no es lo más común. Si las realidades económicas son modificables, sería absurdo estudiarlas con absoluta indiferencia, o modificarlas arbitrariamente, o intervenir para mal. Lo único deseable es intervenir para bien. Esto crea una promesa de felicidad, que parece muy poco científica, pero que está presente en todos los esfuerzos teóricos.

La economía promete felicidad, por eso decepciona. Llamar a la economía "dismal science" implica una esperanza fallida: que la ciencia económica haga venir días buenos. A los astrónomos, nadie les reprocha la aparición de los cometas, aunque auguren días malos. A los meteorólogos se les reprochan sus predicciones fallidas, pero nadie los considera causantes de la lluvia. En cambio, a los economistas se les reprochan sus predicciones fallidas $y$ 
además el subdesarrollo, la inflación, el desempleo, las crisis, la mala distribución del ingreso, la miseria.

Lo que se espera de los economistas es que estudien las realidades económicas y las modifiquen para bien. En cierto sentido fundamental, un economista que acepte la miseria o la inflación con la misama resignación con que un astrónomo acepta los eclipses, no es un verdadero economista. La economía es administrativa. Aunque se preocupa (como debe ser) por la exactitud, siempre está preocupada por algo más importante: modificar para bien, hacer que vengan días buenos. El fantasma de la economía es la felicidad. Es un fantasma perturbador de sus esfuerzos teóricos, porque la felicidad rebasa el marco de las teorías económicas, y sin embargo las preside.

Todo verdadero economista es un reformador social. Keynes decía, con razón, que un economista que fuera solamente economista nunca sería un gran economista. Pero también decía, y también con razón, que los economistas tienen que ser como cualquier dentista: competente y profesional.

No es fácil que se cumpla esta doble exigencia. El prestigio profesional de un economista no depende de lo que opinen sus pacientes en el sillón o el público lector en el sillón. Si (como un buen dentista) hace magníficos estudios de proyectos concretos, o actúa como un gran administrador o funcionario, no pasará a la historia profesional: quedará en la "lower economics". Y si escribe para el público en general; con planteamientos teóricos que rebasen el análisis puramente económico, no será bien visto en los medios profesionales. Ni Adam Smith, ni Karl Marx, serían hoy los mejores candidatos al premio Nobel de economía. Parecerían diletantes que teorizan como si fueran simultáneamente economistas, demógrafos, sociólogos, politólogos,psicólogos, historiadores, antropólogos, filósofos, investigadores, escritores, profesores, periodistas, políticos, moralistas. Serían vistos con desconfianza por estudiar la economía en el marco de toda la vida social.

Por supuesto que los ganadores del premio Nobel de economía tienen de hecho opiniones filosóficas, políticas, morales, sociológicas, históricas (a veces muy rudimentarias). Tienen su propia idea de la felicidad y de cómo lograrla. Tratan de ganar amigos e influir sobre las personas para aumentar la felicidad general. Pero la fuente última de su prestigio profesional no re- 
side en sus posiciones extraprofesionales (que, por eso mismo, pueden ser rudimentarias; aunque también es cierto que de esas posiciones pueden venir muchos aplausos o rechazos en los medios profesionales). La aceptación profesional se gana, en primer lugar, demostrando capacidad en los medios profesionales, según el paradigma profesional que rija en ese momento.

El paradigma actual de la ciencia económica se puede observar en las revistas de mayor prestigio profesional. Implica construir teorías muy limitadas, pero muy rigurosas, congruentes, matemáticas, ceñidas estrictamente a lo que es problematizable en términos puramente económicos, corroborables estadísticamente y relevantes para otros investigadores. Esto puede conducir a ejercicios respetables pero bizantinos, aunque lo deseable es que conduzca a sorpresas revolucionarias en la teoría y en la práctica. La mayor felicidad de un economista hoy sería publicar, en una de las revistas de mayor prestigio profesional, un artículo riguroso y revolucionario que tuviera efectos equivalentes a los que tuvo la Teoría general del emplea, el interés y el dinero, de Keynes.

Obsérvese, de paso, que el paradigma profesional ya no es escribir un libro clásico, sino un artículo académico. Obsérvese también que el problema de la felicidad se complica. Se trata de lograr la felicidad general modificando las realidades económicas para bien, a través de artículos que hagan felices a los economistas. Así resulta que el subdesarrollo no sólo tiene los cuellos de botella has ta ahora estudiados, tiene también un cuello de botella teórico: el comité de lectura de las revistas profesionales de mayor prestigio.

Juan José Arreola, en un cuento de science fiction, inventó una máquina bíblica para superar el problema de la riqueza. Una máquina capaz de desintegrar a los camellos, convertirlos en un chorro de electrones, hacerlos pasar por el ojo de una aguja, reconstruirlos del otro lado y conseguir, así, que las riquezas no impidan entrar al reino de los cielos. Haría falta una máquina semejante para superar el problema de la miseria: para lograr la felicidad de los pueblos pese al formato estrecho de las teorías que hacen felices a los economistas.

La miseria no es normal. En todo caso, es tan normal como el paludismo: como una enfermedad que se puede erradicar del planeta. ¿Por qué, entonces, la campaña organizada por la Organización Mundial de la Salud para erradicar el paludismo ha te- 
nido más éxito que los esfuerzos de las Naciones Unidas para erradicar el subdesarrollo? ¿Por qué el interés académico en la teoría del desarrollo, que fue intenso hasta hace relativamente poco, se fue apagando sin que apareciera la teoría rigurosa y revolucionaria que erradicara la miseria?

No pretendo tener una respuesta, pero ofrezco una hipótesis. Hay dificultades teóricas, no sólo prácticas, para acabar con la miseria. El oasis de una teoría que hiciera simultáneamente felices a los economistas y a los pobres, fue un espejismo. Las soluciones prácticas no fácilmente pueden convertirse en teorías de un formato académico respetable. Es más fácil que un camello pase por el ojo de una aguja, que hacer entrar ideas como las de Fritz Schumacher (el autor de Small is beautiful) al reino de los cielos profesionales. Aunque Schumacher fue un estudiante de economía que se ganó el respeto de Keynes; aunque hizo una carrera académica y profesional; aunque fue simultáneamente un economista/dentista y un economista capaz de rebasar sus limitaciones profesionales; aunque propuso un desarrollo alcanzable con pocos recursos, no lo propuso con teorías de un formato bien visto en los medios profesionales.

Ojalá que alguna fundación patrocinara a un equipo de economistas que tradujera las ideas de Schumacher a un formato teórico de mayor prestigio. Si es posible, habría que intentarlo. Tendría las ventajas de la invención de Arreola: desintegrar la felicidad de los pueblos, hacerla pasar por la felicidad de los economistas y reconstituirla del otro lado. Pero quizá es imposible. Quizá muchas realidades tan importantes para Smith, Marx, Schumpeter, Hirschman o Schumacher, nunca se podrán reducir a esos formatos teóricos.

La felicidad de los pueblos, el fantasma perturbador de la ciencia económica, que le impide ser plenamente ciencia, que le exige ser buena administración, se desdobla en otro fantasma que le exige ser plenamente ciencia: el paradigma de las ciencias físicas, la felicidad de los teóricos. En muchas situaciones económicas modelables matemáticamente, el fantasma del rigor científico ha tenido efectos positivos, aunque limitados, y no siempre tan rigurosos. Pero ese avance ha costado un retroceso. Las situaciones económicas no modelables han quedado huérfanas: no hay muchos economistas que quieran ocuparse de lo que ya no confiere prestigio profesional. 
La profesión de economista está sujeta a la economía de las profesiones, a la sociología de las profesiones, a la política de las profesiones. Aunque no todo economista es un homo economicus, sería extraño que la oferta de teorías económicas se orientara a los mercados que pagan menos, prestigian menos o dan menos poder.

Pero las limitaciones teóricas para acabar con la miseria no se reducen a eso. Hay algo más, inherente al problema de teorizar la miseria, a diferencia del paludismo. En el estudio físico de la naturaleza y del ser humano, las realidades físicas se prestan a la división del trabajo intelectual. La investigación física, química, biológica, puede subdividirse en gremios profesionales que tienen sus propios métodos, lenguajes, criterios de demarcación, criterios de rigor, paradigmas, revistas especializadas, comités de lectura, asociaciones, premios, ambiciones, tradiciones, leyendas y tabúes. Pero hay una convergencia material y teórica en la realidad estudiada. Esto permite que la medicina aproveche los resultados de la física, de la química, de la biología, y los integre en una especie de ingeniería del cuerpo humano.

En cambio, no existe formalmente una disciplina integradora de los resultados de la investigación histórica, económica, jurídica, sociológica, etc.: una ingeniería social. Peor aún: las realidades sociales no se prestan a la división del trabajo intelectual. Aunque siempre es bueno que los médicos o ingenieros de distintas especialidades tengan noción de las otras, no es indispensable: pueden hacer su parte de un proyecto común, con la razonable seguridad de que todas las partes funcionarán integradas en el resultado final. El ciclo termodinámico del motor de un automóvil puede estar a cargo de especialistas que no se ocupan del circuito eléctrico. Tiene que haber una convergencia en la chispa eléctrica, y la hay. Ni las realidades materiales ni las teorías lo impiden. Esto hace fértil el reduccionismo, hasta en el estudio del cuerpo humano, que puede ser visto como un conjunto de circuitos eléctricos o de ciclos termodinámicos o de sustancias químicas.

En cambio, cuando se dice que el cuerpo humano no vale más que un dólar (o lo que sea) porque eso valen las sustancias químicas a las cuales se reduce, el reduccionismo no funciona. Una sustancia química no vale lo mismo en el mercado que fue ra del mercado; al mayoreo que al menudeo; químicamente pu- 
ra que mezclada con otras sustancias; como parte de un cuerpo vivo que de un cuerpo muerto. $\mathrm{Y}$, por supuesto, una persona es más que sus elementos químicos, más que un zoon politikon, más que un homo economicus, más que un sujeto jurídico. La sociedad es más que las distintas radiografias de las ciencias sociales. Radiografías que, por otra parte, no son fáciles de integrar, no son muy convergentes entre sí.

A lo largo del siglo $\mathrm{xx}$, se ha visto una prodigiosa convergencia de las ciencias físicas y naturales: la astronomía, la física, la química, la biología, convergen en las realidades moleculares y convergen entre sí teóricamente. Aunque tienen grandes zonas divergentes, donde no se ocupan de lo mismo, ni de la misma manera, tienen elementos últimos comunes, tanto materiales como teóricos. No se ha visto nada parecido en las ciencias sociales, aunque precisamente en este siglo han prosperado como nunca.

Quizá porque la práctica no tiene sustancia, aunque es analizable desde mil puntos de vista, su reducción a elementos comunes de la realidad o la teoría resulta muy difícil. Los mismos hechos, analizados por distintas ciencias sociales, y hasta por distintas escuelas de un mismo campo, arrojan resultados sin elementos comunes, cuando no excluyentes. La miseria puede ser vista como explotación y el desarrollo como liberación; o como marginación e integración; o como diferencia y aculturación; o como tradición y progreso; o como idolatría y catequesis; o como ignorancia y educación; o como falta y acumulación de recursos; o como desempleo y empleo; o como desnutrición y alimentación; o como apatía y motivación; o como desorden y organización; o como exceso de población y control natal; o como agricultura tradicional e industria moderna. Algunas de estas radiografías pueden ser convergentes entre sí, pero no muchas, ni fácilmente; y, por lo general, con más dificultades teóricas que prácticas.

Un buen promotor con experiencia en proyectos de desarrollo, puede enriquecer su visión de la realidad con estas múltiples radiografías; puede ser más eficaz volviéndose en parte economista, antropólogo, moralista, abogado, psicólogo, empresario, historiador. Pero ¿dónde se da esta convergencia? En una sabiduría administrativa que integra aprendizajes de la teoría y de la práctica, que no se puede asignar a ningún departamento académico y no se puede resumir en un artículo matemático. 
Alguna vez me tocó ver en acción a uno de esos admirables promotores: Arturo Espinosa, en un pueblo de Michoacán. Disponía de fondos de la Fundación Mexicana para el Desarrollo Rural, y escuchaba a un grupo de campesinos que quería iniciar una pequeña empresa avícola. El proyecto parecía viable, pero el promotor parecía escéptico: enumeraba todo lo que podía salir mal, preguntaba a quién se iba a hacer responsable de tal o cual cosa, escuchaba atentamente. Finalmente, puso ciertos requisitos y dijo que, una vez cumplidos, lo iba a estudiar. A mí me extrañó tanta resistencia, y le pedí explicaciones. Su respuesta fue sabia:

Es obvio que el proyecto parece económicamente viable. Hemos apoyado otros semejantes que han salido bien. Pero la viabilidad no depende únicamente del mercado, de los precios, de los costos, de la inversión. Depende, en último término, de si va a ser un proyecto mío o de ellos. Si ellos creen que pueden, si ellos lo pelean, si ellos me lo ganan, es probable que salga bien. Los proyectos que aacen de las buenas intenciones de un promotor son, para empezar, diez veces más grandes de lo que debían ser. Rebasan la capacidad de los supuestos beneficiarios, los aplastan, los hacen perder la iniciativa, los vuelven dependientes del promotor. Y, a veces, los promotores cometen errores obvios, que los campesinos, por deferencia, nunca les dirán. Si el promotor está feliz con su proyecto," ¿por qué arruinar su felicidad?

Los promotores del desarrollo, como los teóricos del desarrollo, quieren la felicidad de los pobres, pero tienen derecho a su propia felicidad. Es una felicidad que los números estadísticos confirmen una hipótesis teórica. Es una felicidad emprender una obra mayúscula en una zona marginada. Pero ¿cómo hacer felices simultáneamente a los benefactores y a los beneficiarios? Lo ideal sería un desarrollo teórico que llevara a un desarrollo práctico, con resultados felices para ambas partes. Pero no parece fácil. Hasta parece haber una relación perversa entre el desarrollo económico y los economistas. Edmundo Flores, uno de los pocos economistas mexicanos con sentido del humor, dijo alg: $d$ na vez que la economía mexicana había funcionado bien hasta que llegaron los economistas. Con cierta injusticia, puede decirse que el llamado milagro económico mexicano lo construyeron los abogados y lo destruyeron los economistas. Lo cual, naturalmente, no demuestra que unas especialidades sean mejores que 
otras. Más bien indica que el desarrollo práctico rebasa cualquier campo teórico, por lo cual un especialista con buena cultura general y experiencia práctica, puede actuar fuera de su especialidad y obtener buenos resultados en la construcción social.

Se dice que Kant trató de ser un Newton de la filosofía y Marx un Darwin de la historia. Hasta la fecha, las ciencias sociales siguen perturbadas por tratar de ser lo que no son: ciencias físicas o naturales. Pero son ciencias de la práctica, que tienen más afinidad con la sabiduría administrativa que con las ciencias puras. Su mejor modelo serían las humanidades. Deberían ser las nuevas humanidades y aceptar el principio: Nada de lo humano me es ajeno.

La práctica social no sólo es multidimensional para efectos de estudio, como las realidades físicas; es inabarcable fuera de la práctica. Da imágenes muy inadecuadas en las radiografias pretendidamente científicas. Por eso la novela, el teatro, la poesía, el ensayo, han producido hasta ahora mejores síntesis de la práctica que las ciencias sociales. Por eso los grandes economistas frecuentaron la literatura y practicaron el ensayo. Adam Smith dio conferencias de literatura, recientemente publicadas. En casa de Marx, como un rito, se leían las obras completas de Shakespeare. Ambos escribieron libros clásicos.

A diferencia de las realidades en las cuàles convergen las ciencias físicas y naturales, las realidades sociales no tienen un sustrato último ajeno a la inteligencia humana. Al estudiar las realidades sociales, la inteligencia humana se estudia a sí misma. Por eso los reduccionismos, fértiles en otros campos, rinden poco en las ciencias sociales. La economía no se entiende más que en el contexto de toda la vida humana. Por eso el estudio de ta economía, a diferencia del estudio del cosmos, puede ser una "dismal science": porque sueña con la felicidad de los pueblos y con su propia felicidad. 